\title{
Pharmacological evaluation of ethnomedicinal Glycosmis pentaphylla Lour. as antidiabetic, antioxidant and cytotoxic agent
}

\author{
Mohammad Oliur Rahman ${ }^{1 *}$, Mohammad Badiur Rahman ${ }^{1}$, Shah Alam Siddiqui², Mohammad Abul Hassan ${ }^{1}$, Mohammad \\ Abdur Rashid ${ }^{3}$ \\ ${ }^{1}$ Department of Botany, University of Dhaka, Dhaka, Bangladesh. \\ 2Department of Applied Chemistry and Chemical Engineering, Islamic University, Kushtia, Bangladesh. \\ ${ }^{3}$ Department of Pharmaceutical Chemistry, University of Dhaka, Dhaka 1000, Bangladesh.
}

\begin{tabular}{l}
\hline ARTICLE INFO \\
\hline Received on: 08/08/2018 \\
Accepted on: $19 / 10 / 2018$ \\
Available online: $30 / 11 / 2018$ \\
\\
\hline Key words: \\
Antidiabetic, DPPH, brine \\
shrimp lethality, cytotoxicity, \\
Glycosmis pentaphylla.
\end{tabular}

\begin{tabular}{l}
\hline ABSTRACT \\
\hline In this study, an ethnomedicinal plant Glycosmis pentaphylla Lour. has been investigated for its pharmacological potential \\
including antidiabetic, antioxidant, and cytotoxic activities. In the investigation of antidiabetic activity, diabetic induced \\
rats were received methanol extract repeatedly for consecutive 3 weeks. This treatment with the extracts resulted in a \\
reduction of the blood glucose level to $33.82 \%, 24.38 \%$, and $9.59 \%$ after 7,14 , and 21 days of treatment, respectively. In \\
this case, statistically significant blood glucose lowering potential of methanol leaf extract at a dose of $250 \mathrm{mg} / \mathrm{kg}$ body \\
weight (bw) was found. In 2,2-diphenyl-1-picrylhydrazyl radical scavenging assessment, moderate antioxidant activity \\
was observed for crude methanol extract with an $\mathrm{IC}_{50}$ value of $46.75 \mu \mathrm{g} / \mathrm{ml}$. In brine shrimp lethality evaluation, the \\
methanol extract showed significant cytotoxicity with an $\mathrm{LC}_{50}$ value of $22.55 \mu \mathrm{g} / \mathrm{ml}$. Our study testifies that methanol \\
extract of Glycosmis pentaphylla has promising pharmacological activities and explored these species as a potential \\
source of active secondary metabolites for pharmaceutical and agrochemical industries.
\end{tabular}

\section{INTRODUCTION}

Diabetes mellitus (DM) is a chronic disorder where the body is unable to regulate the carbohydrate metabolic process appropriately due to insufficient production of insulin or improper responding to insulin. As a result, the body fails to maintain proper sugar level in the blood stream. Diabetes may badly affect blood vessels leading to stroke or heart attack, kidney failure, and even it can cause irreparable damage to eyes, feet, and nerves (Rubin et al., 2012). As per reports from International Diabetes Foundation (IDF), high blood glucose is the third major cause of premature mortality following high blood pressure and tobaccoinitiated diseases. Over $8.8 \%$ of world population are suffering from diabetes and this number is estimated to rise $10.47 \%$ (642 million) by 2040 (IDF, 2013). In Bangladesh, with a total population estimated

\section{"Corresponding Author}

M. Oliur Rahman, Department of Botany, University of Dhaka, Dhaka, Bangladesh.E-mail: oliur.bot@du.ac.bd; prof.oliurrahman@gmail.com
160 million, has the highest number of people suffering from diabetes among all the countries (IDF, 2013). There are 7.1 million recognized patients with DM in Bangladesh and almost an equal number with undetected diabetes (IDF, 2013). This increasing rate of diabetes is now imposing devastating impacts on the national health care system. Tragically, majority of these diabetes patients live under poverty and most of them are unable to afford modern inventions to manage and counter the health complications of diabetes. Therefore, the majority of them depend on the traditional and alternative medicine system to seek remedy and manage their sickness.

Antioxidants are chemical agents which can resist oxidation process either by inhibiting free ions or reducing oxidative stress. Oxidative stress play very important role in developing different diseases, e.g., coronary heart diseases, cancer and aging (Ames et al., 1993) and synthetic antioxidants, e.g., butylated hydroxyanisole (BHA), butylated hydroxytoluene (BHT), propyl gallate (PG), and so on are being used for decades, but recently, different studies have already shown that the use of these synthetic antioxidants are not safe due to their long-run adverse effect, e.g., carcinogenesis, tissue injury, cardiovascular disease, 
atherosclerosis, hypertension, and ischemia/reperfusion injury (Adwan and Mhanna, 2008; Valko et al., 2007). Consequently, the quest for safer natural antioxidants is increasing day-by-day solely based on ethnomedicinal plants.

Plant-derived bioactive compounds generally possess great medicinal values as most of them are evolved as a part of the chemical defense against various infections (Cox and Balick, 1994). These bioactive compounds are known as secondary metabolites and further classified into different groups, e.g., alkaloids, flavonoids, phenols, tannins, terpenes, terpenoids, and so on. Many medicinal plants have multi-functional benefits and they are found to have secondary metabolites which act as anticancer and strong antioxidant agents (Yusuf et al., 2009). As a consequence, the ethnomedicinal/alternative medicinal practices are established based on the use of plant-derived bioactive compounds globally.

Glycosmis pentaphylla (Retz.) A. DC., known as a tooth brush tree is a member of the family Rutaceae and is distributed in Bangladesh, India, Malaysia, Southern China to Philippines, and Australia (Wang et al., 2006). Being an ethnomedicinal plant, different parts of this species are employed for the treatment of several diseases. Roots of this species are used for the treatment of inflammation, rheumatism, jaundice, and anaemia (Rahmatullah et al., 2010). The root, stem, and leaf are administered in folklore medicine in Kerala and Tamil Nadu of India to cure fever and rheumatism (Balachandran et al., 2000). Grinded roots with water are taken in early morning to cure abdominal pain. Extracted leaf juice is applied in liver complaints and fever (Sreejith et al., 2012). In Bangladesh, the plant is widely used as a healing agent against cancer (Panda, 2002).

In the recent past, a number of reports on phytochemical analysis of $G$. pentaphylla have been published. Some of the major classes of compounds reported from $G$. pentaphylla include terpenoids, amides, imides, alkaloids, coumarin, and flavonoids (Sreejith et al., 2012). Several authors investigated the plant for anti-inflammatory efficacy (Ahmed et al., 2000), hepatoprotective activity (Nayak et al., 2011), antimicrobial effect (Amran et al., 2011), and antipyretic potential (Mandal et al., 2011). Previous studies emphasized mostly on identifying different phytochemicals and revealing their medicinal value profile (Murugan and Natarajan, 2016; Sreejith et al., 2012), however, investigation to uncover its various biological activities is very scanty. This study was undertaken to investigate the antidiabetic efficacy of $G$. pentaphylla deploying alloxan-induced animal model and to evaluate its antioxidant activity by 2,2-diphenyl-1-picrylhydrazyl (DPPH) free radical scavenging method. In addition, as the plant is being used against cancer, the cytotoxicity of the plant is also investigated using brine shrimp lethality assay.

\section{MATERIALS AND METHODS}

\section{Plant materials}

Glycosmis pentaphylla, collected from Joydebpur under Gazipur district of Bangladesh in July 2017, was employed in the investigation to assess its biological activities. The identification of these species was confirmed by Professor Dr. Md. Abul Hassan of the Department of Botany, University of Dhaka. Fresh leaves were used for determining the antidiabetic, antioxidant, and cytotoxic activities of this indigenous medicinal plant.

\section{Chemicals}

Alloxan monohydrate, DPPH, BHT, dimethyl sulphoxide (DMSO), and vincristine sulphate (VS) manufactured by SigmaAldrich (St. Louis, MO) were deployed in our investigations. Glibenclamide (Squire Pharmaceuticals Ltd., Bangladesh), Methanol manufactured by Merck (Darmstadt, Germany) and for any other reagents, only analytical grade chemicals (Sigma and Merck) were selected for the study.

\section{Antidiabetic activities}

\section{Preparation of plant extract}

The leaves were washed, kept in room temperature for complete drying, and then the dried leaves were converted to powder form by the electric blender. Leaf powder was then stored in airtight bottles free from moisture and humidity. About $150 \mathrm{~g}$ of powder was flooded with $500 \mathrm{ml}$ of distilled methanol for 72 hours with occasional shaking and stirring at normal room temperature. The mixture was then passed through filtration process and subsequent evaporation by rotary evaporator at $40^{\circ} \mathrm{C}$ which yielded $5.8 \mathrm{~g}$ of residue. This crude methanolic extract (CME) was employed further for studying biological activities.

\section{Experimental animals}

Healthy adult Wister albino rats (110-130 g) of either sex, aged 2-3 months were purchased from the animal house of Jahangirnagar University, Savar, Bangladesh and used in this study. The rats were kept in a spacious polypropylene cages lined with husk in standard environment condition of $25^{\circ} \mathrm{C} \pm 2{ }^{\circ} \mathrm{C}$ with a relative humidity of $55 \% \pm 10 \%$. The light and dark cycle were maintained as 12 hours light period and 12 hours dark period. The rats were fed on a standard pellet diet and had free access to water except the fasting period. Fasting blood glucose level of each rat was determined. All the animals used in this study were handled as per the guidelines of the National Institute of Health for the Care and Use of Laboratory Animals (NIH Publication revised in 1996).

\section{Induction of diabetes}

All the selected Wister albino rats were maintained so as to be fasted over dark period ( 12 hours) and then they were weighted and their blood glucose levels were measured using ACCUANSER DIGITAL blood glucometer and recorded accordingly. To induce diabetes, alloxan monohydrate $(120 \mathrm{mg} / \mathrm{kg}$ bw) was injected interperitoneally. Alloxan monohydrate was weighted first according to the rat's body weight and then the weighted amount of alloxan monohydrate was dissolved in sodium citrate ( $\mathrm{pH} 4.5$ ) solution, and then the solution was administrated to that specific rat. The animals were allowed to access food and water after 30 minutes of injection and after 72 hours, blood glucose level was measured using ACCU-ANSER DIGITAL blood glucometer. The rats with more than $162 \mathrm{mg} / \mathrm{dl}$ or $9.0 \mathrm{mmol} / \mathrm{l}$ of blood glucose level were considered as diabetic rats and selected for the study.

\section{Experimental design}

After selection of 20 animals, they were divided into four different groups comprising five rats in each group. Group-I 
was served as non-diabetic control group. Animals in Group-II, III, and IV were alloxan-induced diabetic rats. Animals of GroupII were left untreated and used as negative control and the animals of Group-III were treated with glibenclamide ( $5 \mathrm{mg} / \mathrm{kg}$ bw/day) which were used as standard group. Rats in Group-IV were forced-fed orally with $G$. pentaphylla CME (250 mg/kg bw/day) and this dose was chosen based on an earlier study where the crude extracts of $G$. pentaphylla $(250 \mathrm{mg} / \mathrm{kg} \mathrm{bw})$ were found to produce a significant pharmacological effect (Khatun et al., 2012). Animals were treated with those specific doses of methanol leaf extract and glibenclamide for consecutive 3 weeks ( $1 \mathrm{ml} / \mathrm{rat})$. For oral administration, specific doses of extracts and glibenclamide were dissolved in distilled water and given to the animal. Group-I and II received only the distilled water.

\section{Determination of blood glucose levels}

To measure fasting blood glucose levels, the animals were made to fast for 12-14 hours on days 0 (start of treatment), 7,14 , and 21 (end of the treatment) followed by collecting blood samples from the tail vein, and glucose levels were measured by using a glucometer.

\section{Determination of DPPH radical scavenging activity assay}

The assessment of DPPH radical scavenging activity was carried out using the method described by Blois (1958). Specified doses of extracts and BHT were taken into $2.9 \mathrm{ml}$ of DPPH in methanol $0.004 \%(\mathrm{w} / \mathrm{v})$ solution and after vigorous shaking, the mixture was undergone through incubation at normal room temperature for a period of 30 minutes. At $517 \mathrm{~nm}$, the absorbance was measured using a blank. Diminishing absorbance of DPPH

$$
I \%=\left[\frac{\left(A_{\text {blank }}-A_{\text {sample }}\right)}{A_{\text {blank }}}\right] \times 100
$$

solution refers to DPPH radical-scavenging activity. To calculate the inhibition percentage $(I \%)$, the following equation was used:

Here, $A_{\text {blank }}$ denotes the absorbance by the blank solution used and $A_{\text {sample }}$ refers to absorbance by sample solution. The $\mathrm{DPPH}$ scavenging ability is expressed as $\mathrm{IC}_{50}$ and this value refers to the concentrations of test specimen which is capable to scavenge $50 \%$ of the free DPPH radical present within the assay medium. Regression equation obtained from concentrations of test specimens was used to calculate the respective $\mathrm{IC}_{50}$ value. Commercially available BHT was taken as a standard and the experiment was performed thrice for all of the samples.

\section{Brine shrimp lethality assay}

The methanol leaf extract $G$. pentapgylla was tested for cytotoxicity following the procedure of Meyer et al. (1982). Artemia salina leach (brine shrimp eggs) were hatched in seawater in a small tank and allowed 1 day to be matured as nauplii. The nauplii were counted with visual examination and 10 nauplii were placed in each of the experimental vials which contained around $5 \mathrm{ml}$ simulated sea water. VS was used as the positive control in this assessment. Different concentrations ranging from 0.78 to $400 \mu \mathrm{g} / \mathrm{ml}$ of extracts and VS were prepared by dissolving in DMSO. Then various concentrations of samples and VS were added to the nauplii contained vials by micropipette. For negative control, only the DMSO $(100 \mu \mathrm{l})$ was added in the experimental vials. All the analyses were carried out in triplicate. All the vials were left 24 hours and then inspected with the help of magnifying glass against a lighted background and the numbers of survivor nauplii were counted. The relation between the mortality and concentrations was analyzed by linear regression to calculate median lethal concentration $\mathrm{LC}_{50}$ values. $\mathrm{LC}_{50}$ value referred to the concentrations of the test specimens needed to bring the mortality to half of the test subjects after the specified test period.

\section{Statistical analysis}

All values were expressed as mean \pm SEM. Data were analyzed using one-way analysis of variance followed by Student's $t$-test. The results were considered statistically significant if $p<0.05$.

\section{RESULTS AND DISCUSSION}

\section{Antidiabetic activity}

The diabetic rats were received the methanol extract once a day for consecutive 21 days and the efficacy of methanol extracts of $G$. pentaphylla in controlling elevated blood glucose level of fasting rat is shown in Figure 1 . The dose $(250 \mathrm{mg} / \mathrm{kg})$ of the extract used in this antidiabetic test was chosen based on an earlier study where Khatun et al. (2012) found that G. pentaphylla crude extracts at $250 \mathrm{mg} / \mathrm{kg}$ bw dose was capable enough to produce significant pharmacological effect.

Alloxan monohydrate is now being widely used to induce DM in experimental animal (Carvalho et al., 2003). Generally, administration of a single dose (120 mg/kg bw) of alloxan monohydrate is sufficient enough to induced DM in rats and we observed the elevated level of glucose in fasting blood collected from the tail of rats after 48 hours of administration. Generally, Alloxan is accumulated through the glucose transporter 2 which results in selective damage to the pancreatic $\beta$-cells that produce insulin and diminishes the glucose absorption by peripheral tissue and thus brings diabetes to animal body. Moreover, alloxan catalyze and accelerate the redox reaction producing free radicals and all these free radicals cause injury to tissue and results in deregulation and degeneration of ß-cells (Carvalho et al., 2003; Muhtadi et al., 2015).

As expected, we observed a noticeable increase in mean blood glucose level in the diabetic control group to that of normal control group of rats. The blood glucose level of diabetic rats was measured and recorded in 0,7 th, 14 th, and 21 st days of treatment. In this study, it has been observed that the treatment with methanol extract produced statistically significant antidiabetic effect compared with the normal and diabetic control rats used in the experiment $(* p<0.05$ and $* * p<0.01)$.

Table 1 shows the average percentage of decrease in blood glucose levels due to treatment with the methanol extract and standard antidiabetic drugs. The present study reveals that repeated oral administration of methanol extract of $G$. pentaphylla into diabetic rats after 7,14 , and 21 days resulted in the reduction of blood glucose levels to $33.82 \%, 24.38 \%$, and $9.596 \%$, respectively (Table 1) and this results implies to the fact that the $G$. pentaphylla could be served as an alternative ethnomedicinal source in treating diabetes. Methanol extract was found to exert its maximum effect in reducing elevated blood glucose (33.82\%) at 7 days of treatment, whereas, the highest reduction of glucose level 


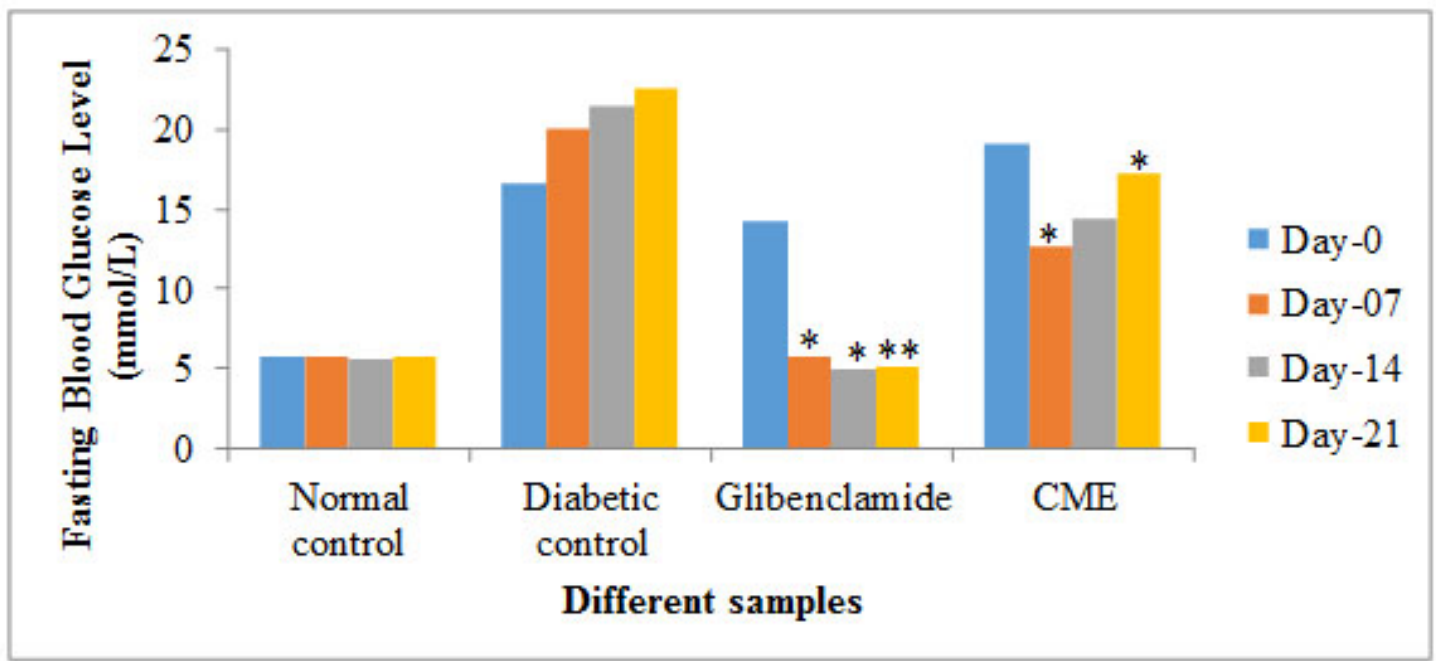

Figure 1. Fasting blood glucose levels (mmol/l) of different groups of rats at different days $\left(^{*} p<0.05\right.$ and ${ }^{* *} p<0.01$ compared with control group).

(65\% reduction) was observed for glibenclamide $(5 \mathrm{mg} / \mathrm{kg} \mathrm{bw})$ after 14 days of treatment.

In this study, methanol extract showed its efficacy in controlling elevated blood glucose level and this antidiabetic effect of methanol extract could be attributed to the different antioxidant phytochemicals, e.g., flavonoids, polyphenols, and tannins available within the extract (Muhtadi et al., 2015). These antioxidants compounds available within the extract might exert individual antidiabetic effect and/or participate in some sort of synergism. The presumed mechanism of action of these antioxidants was based on imitative action on the peripheral tissues by either titillation of reproduction process or discharging of pancreatic excretion of insulin $\beta$-cells. There might be some other mechanism, e.g., acceleration of the glucose discharge from the circulation by increasing filtering rate, renal secretion, and enhancing the discharge of glucose by unregulated metabolic process or integration into fat layer, a process which correlates the pancreas in producing insulin (Muhtadi et al., 2015).

Generally, methanol extract of the plants is found to afford high proportion of compounds belongs to phenolic compounds, saponins, tannins, alkaloids, carbohydrates, glycosides, and flavonoids (Murugan and Natarajan, 2016). Our findings reinforced the ethnomedicinal use of the plant extract in managing diabetes as claimed by traditional healers. However, the specific underlying antidiabetic mechanism is still unclear, and it requires further investigation to uncover the certain mechanism.

\section{Antioxidant activity}

The results of DPPH radical scavenging activities at different concentrations of methanolic extract and standard synthetic antioxidant, tert-butyl-1-hydroxytoluene (BHT) are presented in Table 2. The lower the $\mathrm{IC}_{50}$ values, the higher the scavenging abilities. In this investigation, our tested specimen

Table 1. \% Reduction of blood glucose level at different days.

\begin{tabular}{lccc}
\hline Test specimens & Day 7 (\%) & Day 14 (\%) & Day 21 (\%) \\
\hline Glibenclamide & 60.25 & 65.73 & 63.76 \\
CME & 33.82 & 24.38 & 9.59 \\
\hline
\end{tabular}

exhibited significant efficacy in scavenging the free radicals with $\mathrm{IC}_{50}$ value of $46.75 \mu \mathrm{g} / \mathrm{ml}$ compared with the tert-butyl1-hydroxytoluene (standard) with $\mathrm{IC}_{50}$ value of $21.16 \mu \mathrm{g} / \mathrm{ml}$ (Table 2). The DPPH radical scavenging ability of the extract of G. pentaphylla was found dose-dependent $(p<0.05)$.

Figure 2 displays the dose-response curves representing the abilities of the extracts to scavenge DPPH radical. DPPH radical scavenging abilities were increased with the increased concentration of the test samples. The methanol extract exhibited $81.54 \%$ scavenging activity at $0.5 \mathrm{mg} / \mathrm{ml}$ and our result is consistent with that of Murugan and Natarajan (2016), who investigated free radical scavenging activities of some other extracts of G. pentaphylla and found moderate antioxidant activity.

Phenolic compounds are reported as strong antioxidant compounds in different studies and a significant correlation was observed between phenolic content available within the extracts and DPPH radical scavenging by different extracts (Soobrattee et al., 2005). From some earlier reports, it has been found that the different extracts including methanol extract of $G$. pentaphylla is rich in phenolic content (Murugan and Natarajan, 2016) indicating that phenolic compounds were primarily responsible for this activity.

\section{Cytotoxic activity}

Data obtained from brine shrimp lethality bioassay were used to calculate the $\mathrm{LC}_{50}$ values for the tested specimens. $\mathrm{LC}_{50}$ values were calculated by plotting the percentage mortality of nauplii against respective logarithm of test samples concentrations and regression analysis was performed to draw the curve data to get the best fit line. For the positive control (VS), the $\mathrm{LC}_{50}$ was $0.451 \mu \mathrm{g} / \mathrm{ml}$. The $\mathrm{LC}_{50}$ value of CME was found to be $22.55 \mu \mathrm{g} /$ $\mathrm{ml}$ (Table 3). CME of G. pentaphylla showed the highest lethality activity as compared with VS. The percentage of mortality of shrimp nauplii with the increasing concentration of positive control VS and effect of methanol extracts of Glycosmis pentaphylla is presented in Figure 3. In our study, the CMEs and the VS showed a cytotoxic effect in dose dependent manner as the percentage of the mortality was found to increase with increasing concentrations of VS and CME (Fig. 3). 
Table 2. Evaluation of DPPH free radical scavenging activity of methanol extract of Glycosmis pentaphylla leaves.

\begin{tabular}{|c|c|c|c|c|c|c|}
\hline $\begin{array}{c}\text { Concentration } \\
\quad(\mu \mathrm{g} / \mathrm{ml})\end{array}$ & $\begin{array}{l}\text { Absorbance of the } \\
\text { methanol extracts }\end{array}$ & $\begin{array}{l}\text { Absorbance of } \\
\text { the tert-butyl-1- } \\
\text { hydroxytoluene } \\
\text { (BHT) }\end{array}$ & $\begin{array}{c}\text { Methanol } \\
\text { extract } \\
\text { Inhibition } \\
(\%)\end{array}$ & $\begin{array}{c}\text { tert-butyl-1- } \\
\text { hydroxytoluene } \\
\text { (BHT) inhibition } \\
\text { (\%) }\end{array}$ & $\begin{array}{c}\text { Methanol } \\
\text { extract IC } \\
\quad(\mu \mathrm{g} / \mathrm{ml})\end{array}$ & $\begin{array}{c}\text { tert-butyl-1- } \\
\text { hydroxytoluene } \\
\text { (BHT) } \text { IC }_{50}(\mu \mathrm{g} / \mathrm{ml})\end{array}$ \\
\hline 500 & 0.060 & 0.018 & 81.54 & 94.46 & \multirow{10}{*}{46.75} & \multirow{10}{*}{21.16} \\
\hline 250 & 0.079 & 0.068 & 75.69 & 79.08 & & \\
\hline 125 & 0.113 & 0.097 & 65.23 & 70.15 & & \\
\hline 62.5 & 0.158 & 0.135 & 51.38 & 58.46 & & \\
\hline 31.25 & 0.199 & 0.159 & 38.77 & 51.08 & & \\
\hline 15.625 & 0.224 & 0.175 & 31.08 & 46.15 & & \\
\hline 7.813 & 0.245 & 0.206 & 24.62 & 36.62 & & \\
\hline 3.906 & 0.261 & 0.225 & 19.69 & 30.77 & & \\
\hline 1.953 & 0.286 & 0.238 & 12.00 & 26.77 & & \\
\hline 0.977 & 0.309 & 0.287 & 4.92 & 11.69 & & \\
\hline Blank & \multicolumn{6}{|c|}{ Absorbance $=0.325$} \\
\hline
\end{tabular}
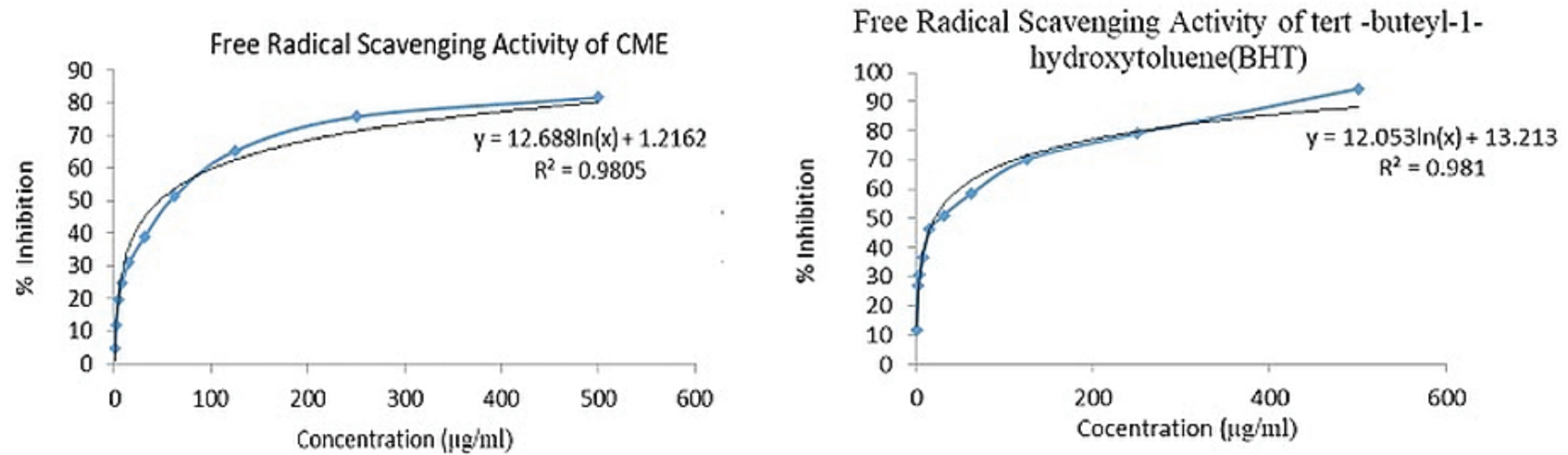

Figure 2. Plot of \% inhibition and predicted regression line of crude methanol extract (CME) and tert-butyl-1-hydroxytoluene (BHT).

Table 3. Brine shrimp lethality profile of the methanol extract of Glycosmis pentaphylla leaves.

\begin{tabular}{cccccc}
\hline $\begin{array}{c}\text { Concentration } \\
(\boldsymbol{\mu g} / \mathbf{m l})\end{array}$ & $\begin{array}{c}\text { \% of mortality } \\
(\mathbf{V S})\end{array}$ & $\begin{array}{c}\mathbf{L C}_{\mathbf{5 0}_{0}} \\
(\boldsymbol{\mu g} / \mathbf{m l}) \mathbf{V S}\end{array}$ & $\begin{array}{c}\text { Concentration } \\
(\boldsymbol{\mu g} / \mathbf{m l})\end{array}$ & $\begin{array}{c}\text { \% of mortality } \\
(\text { methanol } \\
\text { extract })\end{array}$ & $\begin{array}{c}\mathbf{L C}_{\mathbf{5 0}}(\boldsymbol{\mu g} / \mathbf{m l}) \\
\text { methanol } \\
\text { extract }\end{array}$ \\
\hline 0.039063 & 20 & & 0.78125 & 0 & \\
0.078125 & 30 & & 1.5625 & 0 & \\
0.15625 & 30 & & 3.125 & 0 & \\
0.3125 & 40 & & 6.25 & 10 & \\
0.625 & 50 & 0.451 & 12.50 & 20 & 2.55 \\
1.25 & 70 & & 25 & 30 & \\
2.5 & 80 & & 50 & 90 & \\
5 & 80 & & 100 & 100 & \\
10 & 90 & & 200 & 100 & \\
20 & 100 & & 400 & 100 & \\
\hline
\end{tabular}

The brine shrimp lethality bioassay (BSLA) is widely used for preliminary screening of cytotoxic properties of different crude extracts and isolated compounds. In several studies, it has been found that there is a significant correlation between BSLA results and cytotoxicity or anti-tumor activity (Krishnaraju et al., 2005). The $\mathrm{LC}_{50}$ values obtained from the present investigation indicated that the methanol extracts of $G$. pentaphylla has noticeable cytotoxic bioactivity.
Different chemical classes compound obtained from plants such as terpenoids steroids, saponins, lignin, and quinones are reported to have antitumor and cytotoxic activity (Ripa et al., 2009). Therefore, it can be presumed that the methanol extract might afford those cytotoxic compounds which might play an underlying role or might participate some sort of synergism to exert the ovicidal and larvicidal properties (Ripa et al., 2009). Consequently, observed toxicity is enunciating 


\section{Effect of crude methanolic extract (CME) on Brine shrimp nauplii}

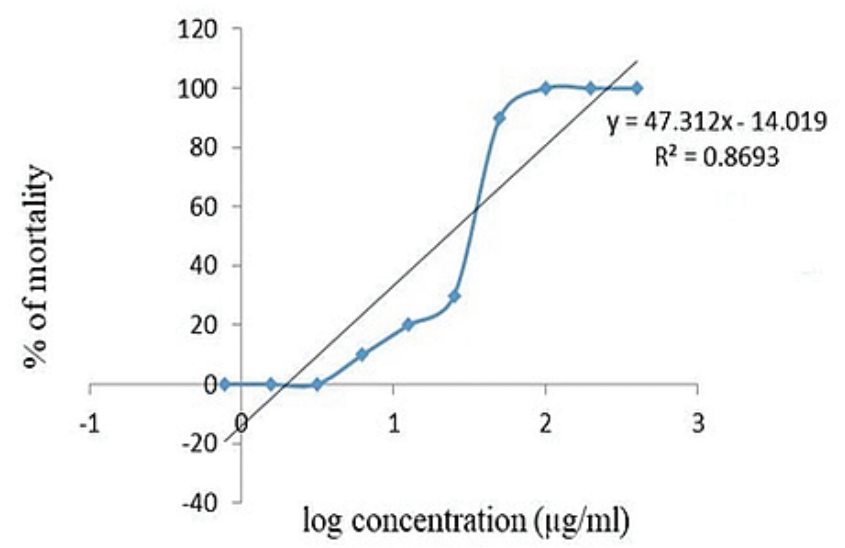

Effect of Vincristine sulphate (positive control) on shrimp nauplii

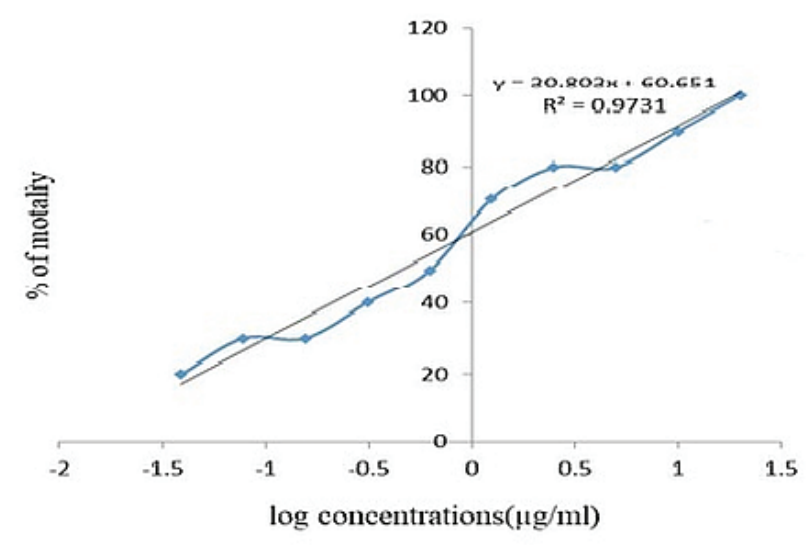

Figure 3. Plot of $\%$ mortality and predicted regression line of CME and VS

that the plant extract could be selected for further studies for isolating responsible bioactive compounds and investigates the compounds using different bio-chemical techniques to uncover the fundamental mechanism of cytotoxicity and to establish it as anti-cancer medicine.

\section{CONCLUSION}

In this study, we have investigated the methanol extract of a widely used ethnomedicinal plant $G$. pentaphylla to determine its usefulness as antidiabetic, antioxidant, and cytotoxic agent. The methanol extract of G. pentaphylla showed significant antidiabetic effect on alloxan-induced Wister albino rats. The test extracts also found to have promising antioxidant effect in DPPH radical scavenging assessment and cytotoxic potential in brine shrimp lethality test. Therefore, the chemical components of the plant extract might assist in averting diabetic problems and act as an alternative in the present armamentarium of antidiabetic drugs and commercially available antioxidants. Our results could also be considered as scientific backing for the folklore usage of $G$. pentaphylla in Bangladesh for treating different ailments and offer opportunity to explore these species as source potential bioactive compounds.

\section{ACKNOWLEDGMENTS}

The authors are thankful to Professor Dr. Sk. Nazrul Islam, Institute of Food and Nutrition Science, University of Dhaka for their help and cooperation. The financial support for carrying out the study from the Ministry of Science and Technology, Government of the People's Republic of Bangladesh is gratefully acknowledged.

\section{CONFLICT OF INTEREST}

We declare no conflict of interest.

\section{REFERENCES}

Adwan G, Mhanna M. Synergistic effects of plant extracts and antibiotics on Staphylococcus aureus strains isolated from clinical specimens. J Sci Res, 2008; 3:134-9.

Ahmed R, Choudhury S, Vajczikova I, Leclercq PA. Essential oils of Glycosmis pentaphylla (Retz.) Correa. A new report from Assam, India. J Essen Oil Res, 2000; 12:471-4.
Ames BN, Shigenaga MK, Hagen TM. Oxidants, antioxidants, and the degenerative diseases of aging. Proc Acad Sci USA, 1993; 90:7915-22.

Amran H, Farhana R, Shapna S, Mohammad RR, ShamsUd-Doha KM, Rumana M, Apurba SA. Antimicrobial, antioxidant and cytotoxic effects of methanolic extracts of leaves and stems of Glycosmis pentaphylla (Retz.) Correa. J App Pharm Sci, 2011; 8:137-40.

Balachandran I, Udayan PS, Harinarayanan MK, Tushar KV. Some common plants used by Kurichiar tribes of Tirunelli forest, Wayanad district, Kerala in medicine and other traditional uses. Indian $\mathrm{J}$ Tradit Knowl, 2008; 7:250-5.

Blois MS. Antioxidant determinations by the use of a stable free radical. Nature, 1958; 181:1199-200.

Carvalho EN, Carvalho NAS, Ferreira LM. Experimental model of induction of diabetes mellitus in rats. Acta Cir Bras, 2003; 18:60-4.

Cox PA, Balick MJ. The ethnobotanical approach to drug discovery. Sci Am, 1994; 270:82-7.

International Diabetes Federation. IDF Diabetes Atlas. International Diabetes Federation. International Diabetes Federation, Brussels, Belgium, p 160, 2013.

Khatun MCS, Mia MP, Ali MA, Rahman MM, Begum K. Antidiabetic and analgesic effects of Glycosmis pentaphylla (Retz.) in Swiss albino mice. Ibrahim Med Coll J, 2012; 6(1): 21-6.

Krishnaraju AV, Rao-Tayi VN, Sundararaju D, Vanisree M, Tsay HS, Subbaraju GV. Assessment of bioactivity of Indian medical plants using brine shrimp (Artemia salina) lethality assay. Int J Appl Sci, 2005; 3:125-34

Mandal S, Upadhyay N, Sharma I, Rohit S, Mandloi A. A comparative antipyretic activity of the crude extracts of the aerial parts of Glycosmis pentaphylla and Bauhinia variegata. Rec Res Sci Tech, 2011; 3:16-18.

Meyer BN, Ferrigni NR, Putnam JE, Jacobsen LB, Nichols DE, Mclaughlin JL. Brine shrimp: a convenient general bioassay for active plant constituents. Planta Med, 1982; 45(5):31-4.

Murugan N, Natarajan D. Phytochemical, antioxidant and antibacterial activities of Glycosmis pentaphylla (Rutaceae) leaf extracts against selected multi-drug resistant bacteria's. J Chem Pharm Res, 2016; 8(1):737-44.

Muhtadi, Primarianti AU, Sujono TA. Antidiabetic activity of Durian (Durio zibethinus Murr.) and Rambutan (Nephelium lappaceum L.) fruit peels in alloxan diabetic rats. Procedia Food Sci, 2015; 3:255-61.

Nayak SS, Jain R, Sahoo AK. Hepatoprotective activity of Glycosmis pentaphylla against paracetamol induced hepatotoxicity in Swiss albino mice. Pharm Biol, 2011; 49:111-7.

Panda H. Medicinal plants cultivation and their uses. Asia Pacific Business Press Inc., New Delhi, India, pp. 539, 2002. 
Rahmatullah M, Jahan R, Rahman MM, Seraj S, Nasrin D, Khatun Z, Chowdhury AR, Azad AK, Khatun MA, Begum R, Jahan FI. A survey of medicinal plants used by folk medicinal practitioners for treatment of gastrointestinal disorders in randomly selected areas of four districts of Bangladesh. Adv Nat Appl Sci, 2010; 4(2):139-47.

Ripa FA, Haque M, Naharand L, Islam M. Antibacterial, cytotoxic and antioxidant activity of Passiflora edulis Sims. Eur J Sci Res, $2009 ; 31: 592-8$.

Rubin R, Strayer DS, Rubin E. Rubin's Pathology: clinicopathologic foundations of medicine. 6th edition. Lippincott Williams \& Wilkins, Philadelphia, PA, pp. 1081-98, 2012.

Soobrattee MA, Neergheen VS, Luximon-Ramma A, Aruoma OI, Bahorun T. Phenolics as potential antioxidant therapeutic agents: mechanism and actions. Mutat Res Fund Mol Mech Mutagen, 2005; 579:200-13.

Sreejith PS, Praseeja RJ, Asha VV. A review on the pharmacology and phytochemistry of traditional medicinal plant, Glycosmis pentaphylla (Retz.) Correa. J Pharm Res, 2012; 5(5):2723-8.
Valko M, Leibfritz D, Moncol J, Cronin MT, Mazur M, Telser J. Free radicals and antioxidants in normal physiological functions and human disease. Int J Biochem Cell Biol, 2007; 39:44-84.

Wang J, Di Y, Yang X, Li S, Wang Y, Hao X. Hydroquinone diglycoside acyl esters from the stems of Glycosmis pentaphylla. Phytochem, 2006; 67:486-91.

Yusuf M, Begum J, Hoque MN, Chowdhury JU. Medicinal plants of Bangladesh. BCSIR, Chittagong, p 794, 2009.

\section{How to cite this article:}

Rahman MO, Rahman MB, Siddiqui SA, Hassan MA, Rashid MA. Pharmacological evaluation of ethnomedicinal Glycosmis pentaphylla Lour. as antidiabetic, antioxidant and cytotoxic agent. J App Pharm Sci, 2018; 8(11): 080-086. 